\title{
INTRODUCTION TO AN INVESTIGATION OF RACIAL DIFFERENCES IN THE CLINICAL PICTURE OF LEPROSY
}

M. OBERDÖRFFER.

It has been described fairly often that in one race or in one country leprosy tends to take a different clinical course compared with others. I have been studying this question in West Africa, Sudan, Egypt, Ceylon, India and recently, Malaya. The following facts seem to be established from these observations which will be extended further in the near future.

(i) In Nigeria the majority of all cases (90\%) belong to the macular type of lesions and have been found to contain more or less marked tuberculoid structure according to the findings of Wade and his co-operators in other countries. The prognosis of these Nigerian types of leprosy appear to be bad as compared with India and Ceylon. The results of treatment in Nigeria are bad, the relapse rate is high while the definite advance to generalised lepromatous lesions appears to be rare. With regard to type distribution as found in surveys see (M. I. Oberdorffer, Arch. f. Schiffs u Tropenhyg. June, I938).

(ii) In Ceylon leprosy tends to take a very mild course and the prognosis in the many mono-macular cases appears to be good. The incidence is not very high. It may be noted here that in all countries some individuals seem to be unresistant against leprous infection from the start.

(iii) In Calcutta the incidence of leprosy is probably high, though not as high as I found in Nigeria. A good many of these cases are frank tuberculoids and give a very good prognosis with regard to treatment.

(iv) In Malaya as Ryrie will point out later, Indians shew these mild forms of leprosy in striking contrast to the very serious 
course which leprosy tends to take in Chinese. Even early tuberculoid cases tend to become lepromatous. In Malays, more or less, an intermediate type is found.

The very interesting observation in all these countries which I think is new is the following one.

I found in Nigeria that in certain seasons of the year most of the macular lesions are bacteriologically negative while in the other seasons a great number of these more or less tuberculoid lesions become positive (M. I. Oberdorffer, Arch. f. Schiff, u Tropenhyg, July, 1938). This observation could be affirmed in Calcutta and Lowe will report on the findings. The percentage of positive cases in Calcutta in this seasonal variation is not as high as in Nigeria. In Malaya the tuberculoid lesions in Chinese appear to be positive all through the year. Ryrie will detail these observations later. I have been looking for a possible explanation of these facts. In my paper on predisposing causes of leprosy in Nigeria I have detailed my findings and I want to give here only a short account of the results. I could not convince myself that the seasonal variations of bacteriological findings is a consequence of any climatical factor. The geographical distribution of high incidence of leprosy in the tropics brought me on the track of one factor which has never been investigated with regard to leprosy as yet. In all countries with a high incidence of leprosy in the tropics there is a very common food plant called Colocasia antiquorum-the vernacular names of which are given in an appendix. Colocasia antiquorum has been found by Clark to contain a highly toxic sapotoxin-the toxicity of which shews a definite seasonal variation. Details should be looked up in Clark's original papers. The tentative hypothesis which I derive from my observations and findings in Nigeria and elsewhere is the following :-

(i) Colocasia antiquorum forms an important predisposing factor in leprosy.

(ii) In countries with high incidence of leprosy in the tropics, tuberculoid lesions which become seasonally bacteriologically positive and lepromatous prevail if Colocasia is eaten only in certain seasons (Nigeria). The prognosis in these countries as to cure is bad, as to complete change to lepromatous leprosy, the prognosis is good.

(iii) In Ceylon where little or no Colocasia is eaten and the general health of the population is good, the incidence of leprosy is low and the prognosis as to cure and as to lepromatous change is good.

(iv) In India where comparatively little Colocasia is eaten 
and the general health of the population is bad, the incidence of leprosy is high but mild forms prevail generally with good prognosis. It is not certain if the seasonal variations of bacteriological findings in India can be attributed to Colocasia eating. Further investigations seem desirable.

(v) In Malaya, Chinese who eat Colocasia all through the year tend to develop constant lepromatous change in tuberculoid lesions far more frequently. Ryrie will go into the details.

Summarising my observations and my hypothesis, I say that in some countries tuberculoid leprosy shews seasonal variations in bacteriological findings which may possibly be caused by a sapotoxin containing food plants, the Colocasia antiquorum. It is certainly not the only predisposing factor in leprosy but the observations in this matter may be worth while discussing.

[In a later paper Dr. Oberdorffer writes:-

"The author ascribes the seasonal variation and the frequency of lepromatous lesions in some countries to the temporary or habitual intoxication with sapotoxins from aroideal food plants like colocasia (taro, etc.). The mode of action of this sapotoxin is its damage to the adrenals, and the author thinks that toxin or conśtitutional adrenal damage may be a decisive factor in the determination of the manner in which the infected body deals with its infection. Adrenal damage of any kind is likely to cause the temporary or final transition of tuberculoid to lepromatous tissue reaction-which means from non-infective to infective stages."']

Synonyms and Colloquial Names for Colocasia Antiquorum.

West Africa-Coco-Yam; Central Africa-Taro; Egypt and SudanUl'ass or Culcass; India-Kach-chi, Kachu, Aroi ; Ceylon-Kiri-ala, Habar-ala, Daesi-ala, Kand-ala; Malaya-Talla, Ubi Keladek; Java-Bote, Loombo, Tales; Madura-Kaladi; Pacific Islands-Taro; West IndiesTannia, Dasheen, Edoh, Melanga. Colocasia is also caten in: Brazil, Columbia, South China, Japan, Phillipines, Mediterranean Area. 